\title{
Highly sensitive and quantitative evaluation of the EGFR T790M mutation by nanofluidic digital PCR
}

\author{
Eiji Iwama,2, Koichi Takayama², Taishi Harada², Isamu Okamoto³, Fumihiko \\ Ookubo ${ }^{4}$, Junji Kishimoto5, Eishi Baba ${ }^{1}$, Yoshinao Oda ${ }^{6}$ and Yoichi Nakanishi' ${ }^{2,3}$ \\ ${ }^{1}$ Faculty of Medical Sciences, Department of Comprehensive Clinical Oncology, Kyushu University, Fukuoka, Japan \\ ${ }^{2}$ Research Institute for Diseases of the Chest, Graduate School of Medical Sciences, Kyushu University, Fukuoka, Japan \\ ${ }^{3}$ Center for Clinical and Translational Research, Kyushu University Hospital, Fukuoka, Japan \\ ${ }^{4}$ Division of Diagnostic Pathology, Kyushu University Hospital, Fukuoka, Japan \\ ${ }^{5}$ Department of Research and Development of Next Generation Medicine, Kyushu University, Fukuoka, Japan \\ ${ }^{6}$ Department of Anatomic Pathology, Graduate School of Medical Sciences, Kyushu University, Fukuoka, Japan \\ Correspondence to: Eiji Iwama, email: iwama@kokyu.med.kyushu-u.ac.jp \\ Keywords: EGFR, T790M, digital PCR, highly sensitive detection, quantification \\ Received: January 09, $2015 \quad$ Accepted: April 20, $2015 \quad$ Published: May 10, 2015
}

This is an open-access article distributed under the terms of the Creative Commons Attribution License, which permits unrestricted use, distribution, and reproduction in any medium, provided the original author and source are credited.

\section{ABSTRACT}

The mutation of T790M in EGFR is a major mechanism of resistance to treatment with EGFR-TKIs. Only qualitative detection (presence or absence) of T790M has been described to date, however. Digital PCR (dPCR) analysis has recently been applied to the quantitative detection of target molecules in cancer with high sensitivity. In the present study, 25 tumor samples (13 obtained before and 12 after EGFR-TKI treatment) from 18 NSCLC patients with activating EGFR mutations were evaluated for T790M with dPCR. The ratio of the number of T790M alleles to that of activating mutation alleles (T/A) was determined. dPCR detected T790M in all 25 samples. Although T790M was present in all pre-TKI samples from 13 patients, 10 of these patients had a low T/A ratio and manifested substantial tumor shrinkage during treatment with EGFR-TKIs. In six of seven patients for whom both pre- and post-TKI samples were available, the T/A ratio increased markedly during EGFR-TKI treatment. Highly sensitive APCR thus detected T790M in all NSCLC patients harboring activating EGFR mutations whether or not they had received EGFR-TKI treatment. Not only highly sensitive but also quantitative detection of T790M is important for evaluation of the contribution of T790M to EGFR-TKI resistance.

\section{INTRODUCTION}

Treatment with epidermal growth factor receptor (EGFR) tyrosine kinase inhibitors (TKIs) has become the standard care for patients with non-small cell lung cancer (NSCLC) positive for activating mutations of EGFR [1-7]. Several methods based on the polymerase chain reaction (PCR), such as the Scorpion amplification refractory mutation system (ARMS), have been developed for $E G F R$ mutation screening and have a sensitivity that allows the detection of a mutant allele fraction of at least $1 \%$ (one mutant molecule in a background of 99 wild-type molecules) [8-11]. These laboratory tests are now commercially available and are widely used to detect target $E G F R$ mutations in patients for appropriate implementation of treatment with EGFR-TKIs.

Although treatment of patients positive for activating mutations of EGFR with EGFR-TKIs has a pronounced clinical benefit initially, such individuals inevitably develop drug resistance, within $\sim 1$ year on average $[12,13]$. The mutation of threonine-790 to methionine (T790M) in EGFR is a major cause of resistance to EGFR-TKIs, accounting for $\sim 60 \%$ of patients with resistance to these drugs [12-15]. T790M has also been detected in specimens obtained from NSCLC patients before treatment with EGFR-TKIs, with the detection rate for the mutation being dependent on the sensitivity of the technique [16-19]. These previous studies evaluated 
Table 1: Characteristics of the study patients and their history of chemotherapy.

\begin{tabular}{|c|c|c|c|c|c|c|c|c|}
\hline $\begin{array}{c}\text { Patient } \\
\text { no. }\end{array}$ & Sex & $\begin{array}{c}\text { Age } \\
\text { (years)* }\end{array}$ & $\begin{array}{c}\text { Histological or } \\
\text { cytological features }\end{array}$ & EGFR mutation & $\begin{array}{c}\text { History of } \\
\text { EGFR-TKI } \\
\text { treatment }\end{array}$ & $\begin{array}{c}\text { History of } \\
\text { cytotoxic } \\
\text { chemotherapy } \dagger\end{array}$ & $\begin{array}{l}\text { Best clinical } \\
\text { response to } \\
\text { EGFR-TKIst }\end{array}$ & $\begin{array}{l}\text { Total period of } \\
\text { EGFR-TKI } \\
\text { treatment (days) }\end{array}$ \\
\hline 1 & M & 70 & Adeno & L858R & GEF & Yes & PR & 505 \\
\hline 2 & $\mathrm{~F}$ & 68 & Adeno & Ex19 del & GEF & Yes & PR & 2644 \\
\hline 3 & $\mathrm{~F}$ & 73 & Adeno & Ex19 del & GEF & Yes & PR & 686 \\
\hline 4 & F & 70 & Adeno & Ex19 del & GEF, ERL & No & SD & 751 \\
\hline 5 & $\mathrm{~F}$ & 71 & Adeno & L858R & GEF & No & PR & 582 \\
\hline 6 & M & 52 & Adeno & Ex19 del & GEF, ERL & Yes & PR & 527 \\
\hline 7 & $\mathrm{~F}$ & 68 & Adeno & Ex19 del & ERL & Yes & PR & 304 \\
\hline 8 & F & 54 & Adeno & Ex19 del & GEF, ERL & Yes & PR & 373 \\
\hline 9 & F & 68 & Adeno & Ex19 del & GEF & No & PR & 202 \\
\hline 10 & $\mathrm{M}$ & 76 & Adeno & Ex19 del & GEF & Yes & PR & $407 \S$ \\
\hline 11 & F & 61 & Adeno & L858R & GEF, ERL & No & PR & $283 \S$ \\
\hline 12 & $\mathrm{M}$ & 79 & Adeno & L858R/T790M & GEF & Yes & PD & 95 \\
\hline 13 & $\mathrm{~F}$ & 36 & Adeno & L858R/T790M & No & No & NA & NA \\
\hline 14 & $\mathrm{~F}$ & 73 & Adeno & Ex19 del & GEF & Yes & PR & 1635 \\
\hline 15 & $\mathrm{M}$ & 55 & Adeno & Ex19 del & GEF, ERL & Yes & $\mathrm{SD}$ & 428 \\
\hline 16 & $\mathrm{~F}$ & 51 & Adeno & L858R & GEF, ERL & Yes & PR & 910 \\
\hline 17 & $\mathrm{~F}$ & 41 & Adeno & Ex19 del & GEF, ERL & Yes & PR & 494 \\
\hline 18 & M & 50 & Adeno & L858R & GEF & No & PD & 20 \\
\hline
\end{tabular}

Abbreviations: Adeno, adenocarcinoma; GEF, gefitinib; ERL, erlotinib; PR, partial response; SD, stable disease; PD, progressive disease; NA, not applicable.

*Age is that at which treatment with the first EGFR-TKI was started. †Chemotherapy from collection of the pre-TKI sample to that of the post-TKI sample.

†According to the Response Evaluation Criteria in Solid Tumors (RECIST). §These patients (nos.10 and 11) are currently receiving EGFR-TKI treatment without PD.

T790M only with qualitative methods, however. Digital PCR (dPCR) is based on the performance of PCR with a single template molecule and is able to detect targets in a quantitative and highly sensitive manner. This technique has recently been applied to detect target molecules in various cancer types [20-23].

We have now applied dPCR to the quantitative and highly sensitive detection of T790M in specimens obtained from NSCLC patients with activating EGFR mutations either before or after (or both before and after) treatment with EGFR-TKIs.

\section{RESULTS}

\section{Patients and sample collection}

We selected 18 patients whose cytological specimens (including adequate cancer cells) or frozen cell pellets were available from among patients diagnosed with NSCLC positive for major activating mutations of EGFR [L858R or deletions in exon 19 (Ex19 del)] at Kyushu University Hospital between October 2002 and December
2012. The study was approved by the Ethics Committee of Kyushu University.

The characteristics of the 18 patients analyzed in the study are shown in Table 1. All patients had adenocarcinoma positive for activating EGFR mutations confirmed by a conventional PCR-based method. Eleven of the 18 patients were positive for Ex19 del, and seven were positive for L858R. The T790M mutation was also detected by conventional PCR in specimens obtained from two patients (nos.12 and 13) before EGFR-TKI treatment (pre-TKI samples).

Seventeen patients received EGFR-TKI (gefitinib or erlotinib, or both) treatment, whereas one patient positive for T790M received only best supportive care (no anticancer treatment). Of the 17 patients treated with EGFR-TKIs, 13 (76.5\%) achieved a partial response. The treatment period for EGFR-TKIs ranged from 20 to 2644 days (median, 527 days).

A total of 25 tumor samples, including 13 preTKI and 12 post-TKI specimens, was obtained from the 18 patients in the study. Eighteen of the samples were derived from pleural effusion, three from the primary tumor, three from peritoneal effusion, and one from pericardial effusion (Table 2). The samples consisted of 18 
Table 2: Quantitative and qualitative evaluation of T790M in pre-TKI and post-TKI samples by dPCR.

\begin{tabular}{|c|c|c|c|c|c|c|c|c|c|c|c|c|}
\hline \multirow[b]{2}{*}{ Pre-TKI samples* } & \multirow[b]{2}{*}{ Sampling site } & \multicolumn{2}{|c|}{ T790M detection } & \multicolumn{3}{|c|}{ Input DNA (ng) applied to each panel } & \multicolumn{3}{|c|}{$\begin{array}{c}\text { Estimated number of target alleles applied to } \\
\text { panels }(1)+(2)\end{array}$} & \multicolumn{2}{|c|}{$\begin{array}{c}\text { Ratio of estimated nos. of } \\
\text { alleles }(\%)\end{array}$} & \multirow[b]{2}{*}{$\mathrm{T} / \mathrm{A}(\%) \dagger$} \\
\hline & & ARMS & $\mathrm{dPCR}$ & Control & $\begin{array}{c}\text { Activating } \\
\text { mutation }\end{array}$ & $\mathrm{T} 790 \mathrm{M}$ & Control & $\begin{array}{c}\text { Activating } \\
\text { mutation }\end{array}$ & $\mathrm{T} 790 \mathrm{M}$ & $\begin{array}{c}\text { Activating } \\
\text { mutation/ } \\
\text { control }\end{array}$ & $\begin{array}{l}\text { T790M/ } \\
\text { control }\end{array}$ & \\
\hline $1-1-\mathrm{C}$ & Pleural effusion & - & + & 2.5 & 2 & 100 & 762 & 400 & 103 & 65.62 & 0.34 & 0.52 \\
\hline $2-1-\mathrm{C}$ & Pleural effusion & - & + & 44.6 & 44.6 & 44.6 & 329 & 10 & 2 & 3.04 & 0.61 & 20.00 \\
\hline $3-1-\mathrm{C}$ & Pleural effusion & - & + & 20 & 40 & 100 & 465 & 454 & 20 & 48.82 & 0.86 & 1.76 \\
\hline $4-1-C$ & Pericardial effusion & - & + & 14 & 28 & 100 & 2911 & 4440 & 87 & 76.26 & 0.42 & 0.55 \\
\hline $5-1-\mathrm{C}$ & Primary lesion & - & + & 14 & 30 & 87.82 & 1901 & 171 & 56 & 4.2 & 0.47 & 11.18 \\
\hline $6-1-\mathrm{C}$ & Primary lesion & - & + & 50 & 50 & 100 & 511 & 101 & 2 & 19.77 & 0.2 & 0.99 \\
\hline $7-1-C$ & Primary lesion & - & + & 17.46 & 17.46 & 17.46 & 1484 & 448 & 2 & 30.19 & 0.13 & 0.45 \\
\hline $8-1-F$ & Pleural effusion & - & + & 3 & 25 & 100 & 1124 & 1213 & 7 & 12.95 & 0.02 & 0.14 \\
\hline $9-1-F$ & Pleural effusion & - & + & 7 & 25 & 100 & 2871 & 2166 & 10 & 21.12 & 0.02 & 0.12 \\
\hline $10-1-\mathrm{F}$ & Pleural effusion & - & + & 5 & 25 & 100 & 1852 & 3184 & 7 & 34.38 & 0.02 & 0.05 \\
\hline $11-1-\mathrm{F}$ & Pleural effusion & - & + & 4 & 30 & 100 & 1498 & 232 & 13 & 2.06 & 0.03 & 1.69 \\
\hline $12-1-\mathrm{C}$ & Pleural effusion & + & + & 5 & 5 & 5 & 658 & 42 & 62 & 6.38 & 9.42 & 147.69 \\
\hline \multirow{2}{*}{$13-1-\mathrm{C}$} & Pleural effusion & + & + & 30 & 60 & 60 & 2744 & 55 & 171 & 1 & 3.12 & 311.59 \\
\hline & Detection rate & $15.4 \%$ & $100 \%$ & & & & & & & & & \\
\hline \multirow[b]{2}{*}{ Post-TKI samples* } & \multirow[b]{2}{*}{ Sampling site } & \multicolumn{2}{|c|}{ T790M detection } & \multicolumn{3}{|c|}{ Input DNA (ng) applied to each panel } & \multicolumn{3}{|c|}{$\begin{array}{l}\text { Estimated number of target alleles applied to } \\
\text { panels (1) + (2) }\end{array}$} & \multicolumn{2}{|c|}{$\begin{array}{l}\text { Ratio of estimated nos. of } \\
\text { alleles (\%) }\end{array}$} & \multirow[b]{2}{*}{$\mathrm{T} / \mathrm{A}(\%) \dagger$} \\
\hline & & ARMS & dPCR & Control & $\begin{array}{c}\text { Activating } \\
\text { mutation }\end{array}$ & $\mathrm{T} 790 \mathrm{M}$ & Control & $\begin{array}{c}\text { Activating } \\
\text { mutation }\end{array}$ & T790M & $\begin{array}{c}\text { Activating } \\
\text { mutation/ } \\
\text { control }\end{array}$ & $\begin{array}{l}\mathrm{T} 790 \mathrm{M} / \\
\text { control }\end{array}$ & \\
\hline $1-2-\mathrm{C}$ & Pleural effusion & - & + & 2.5 & 2.5 & 100 & 1342 & 52 & 1014 & 3.87 & 1.89 & 48.84 \\
\hline $2-2-\mathrm{F}$ & Pleural effusion & - & + & 3 & 30 & 100 & 931 & 798 & 899 & 8.57 & 2.9 & 33.84 \\
\hline $3-2-\mathrm{C}$ & Pleural effusion & + & + & 40 & 40 & 40 & 826 & 1259 & 477 & 152.42 & 57.75 & 37.89 \\
\hline $4-2-\mathrm{C}$ & Pleural effusion & + & + & 12 & 22 & 61.04 & 2283 & 2601 & 4163 & 62.14 & 35.85 & 57.69 \\
\hline $5-2-\mathrm{C}$ & Pleural effusion & - & + & 14 & 30 & 100 & 1448 & 562 & 52 & 18.11 & 0.5 & 2.76 \\
\hline $6-2-\mathrm{C}$ & Peritoneal effusion & + & + & 20 & 28.82 & 28.82 & 3464 & 3505 & 1175 & 70.22 & 23.54 & 33.52 \\
\hline $7-2-\mathrm{C}$ & Pleural effusion & - & + & 14 & 28 & 58.44 & 1324 & 101 & 97 & 3.81 & 1.76 & 46.19 \\
\hline 14-2-F & Pleural effusion & - & + & 3 & 30 & 100 & 1485 & 1207 & 1542 & 8.13 & 3.12 & 38.38 \\
\hline $15-2-C$ & Peritoneal effusion & - & + & 8 & 19.36 & 19.36 & 2261 & 405 & 7 & 7.4 & 0.13 & 1.76 \\
\hline $16-2-\mathrm{F}$ & Pleural effusion & + & + & 3 & 6 & 6 & 1563 & 1334 & 947 & 42.67 & 30.29 & 70.99 \\
\hline $17-2-\mathrm{C}$ & Peritoneal effusion & - & + & 18 & 25 & 94.48 & 1552 & 2936 & 39 & 136.21 & 0.48 & 0.35 \\
\hline \multirow[t]{2}{*}{$18-2-\mathrm{C}$} & Pleural effusion & - & + & 7.44 & 7.44 & 7.44 & 1574 & 111 & 2 & 7.05 & 0.13 & 1.84 \\
\hline & Detection rate & $33.3 \%$ & $100 \%$ & & & & & & & & & \\
\hline
\end{tabular}

${ }^{*} \mathrm{C}$ denotes cytological specimen; $\mathrm{F}$ denotes frozen cell pellet obtained from malignant effusion. Sample designation corresponds to patient no.-1 (pre-TKI sample) or 2 (post-TKI sample)-sample type (C or F).Both pre-TKI and post-TKI samples were available for patients 1 to 7 . $\uparrow \mathrm{T} / \mathrm{A}$, the ratio of the number of $\mathrm{T} 790 \mathrm{M}$ alleles to that of activating mutation alleles.

cytological specimens processed for Papanicolaou staining (C samples) and seven frozen cell pellets obtained from malignant effusion (F samples).

\section{Evaluation of the sensitivity and specificity of nanofluidic dPCR}

We examined the sensitivity and specificity of nanofluidic dPCR for detection of the T790M mutation of EGFR with known DNA samples corresponding to wild-type (WT) or mutant (T790M) alleles of EGFR. No positive signal for T790M was detected from any of the 765 chambers when up to $1.0 \times 10^{4}$ copies of the WT allele were applied to the digital panel as a negative control (Supplementary Table 1). Application of $1.0 \times 10^{5}$ WT copies resulted in the appearance of 0 to 4 nonspecific positive signals in eight replicates. With the use of Poisson regression analysis, we defined the cutoff number of positive signals as 3 (95\% confidence interval, 0.85 to 2.64) for detection of $T 790 \mathrm{M}$ alleles in a sample including $1.0 \times 10^{4}$ to $1.0 \times 10^{5} \mathrm{WT}$ alleles.

The relation between the known number of input T790M alleles and the estimated number by dPCR was linear for 1, 10, 100, and $1000 \mathrm{~T} 790 \mathrm{M}$ alleles in a sample including $1.0 \times 10^{4} \mathrm{WT}$ alleles (Figure 1). These results thus showed that the quantitative evaluation of T790M by $\mathrm{dPCR}$ is reliable and has a sensitivity that allows for the detection of a mutant allele fraction of $0.01 \%$ or more.

\section{Highly sensitive detection and quantitative evaluation of T790M by dPCR}

With the use of the highly sensitive dPCR system, we then evaluated the T790M status of the 25 samples

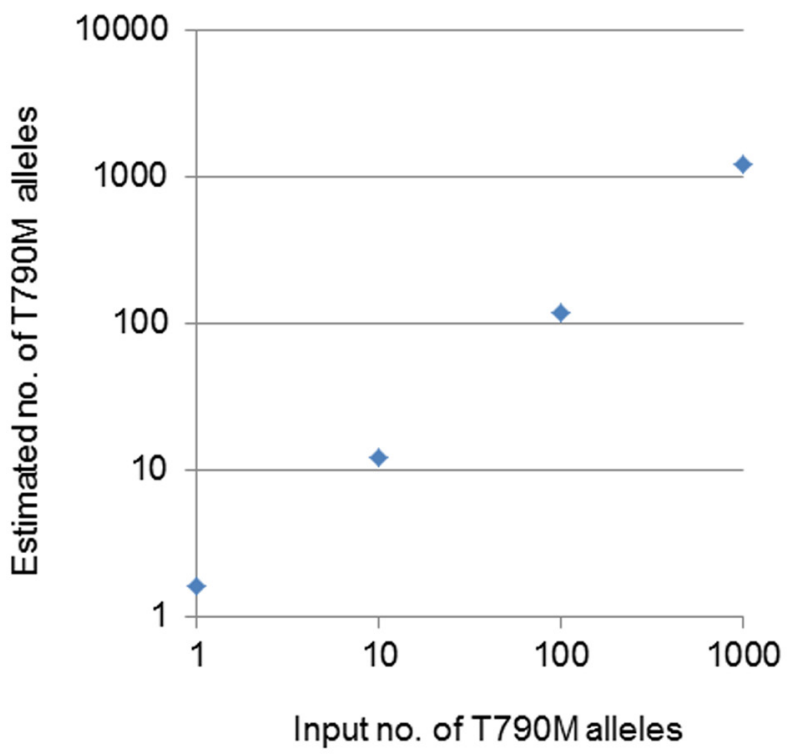

Figure 1: Relation between the number of input T790M alleles and the estimated number of these alleles by dPCR. The input T790M alleles were added to a digital panel together with $1 \times 10^{4} \mathrm{WT}$ alleles. 
obtained from the study patients. dPCR detected T790M in all of these 25 samples, including both pre-TKI $(n=13)$ and post-TKI $(n=12)$ specimens (Table 2$)$. In contrast, ARMS detected T790M in only $15.4 \%$ (2 of 13 ) and $33.3 \%$ (4 of 12 ) of the pre-TKI and post-TKI samples, respectively (Table 2). These data thus suggested that dPCR was able to detect T790M present in a small population of tumor cells at a frequency below the limit of detection for ARMS.

We next evaluated the frequency of T790M in pre-TKI samples. Representative results for one of these samples (1-1-C) from a patient (no. 1) with the L858R mutation of EGFR are shown in Figure 2A. We performed duplicate assays [panels (1) and (2)] for detection of each target allele [L858R, T790M, and control (a region of $E G F R$ exon 2)]. Chambers with a positive reaction are indicated as red squares in a heat map for each of the 765 chambers, and the number of signals was counted by the system software (raw data). The number of target alleles included in the sample applied to the panels was estimated from the raw data with the use of the Poisson distribution (estimated number of target alleles), and the values for the duplicate assays were summed $[(1)+(2)]$. By adjusting the amount of input DNA in each reaction, we calculated the ratio of the number of activating mutation (L858R) or T790M alleles to the number of control alleles as follows: $\mathrm{L} 858 \mathrm{R} /$ control $=(400 \times 5.00) /(762 \times 4.00)=65.62 \%(a)$, and $\mathrm{T} 790 \mathrm{M} / \mathrm{control}=(103 \times 5.00) /(762 \times 200)=0.34 \%$ (b).

To correct for the different proportion of cancer cells and genetic heterogeneity in each sample, we calculated the ratio of the number of $7790 \mathrm{M}$ alleles to the number of activating mutation alleles (T/A) as follows: T/A $=b / a$ $=0.34 / 65.62=0.52 \%$. The T/A $(\%)$ values for all 13 preTKI samples are presented in Table 2 and Supplementary Table 2. The results show that, with the exception of two samples (12-1-C, 13-1-C), the T790M mutation was much less frequent than activating mutations in pre-TKI specimens.

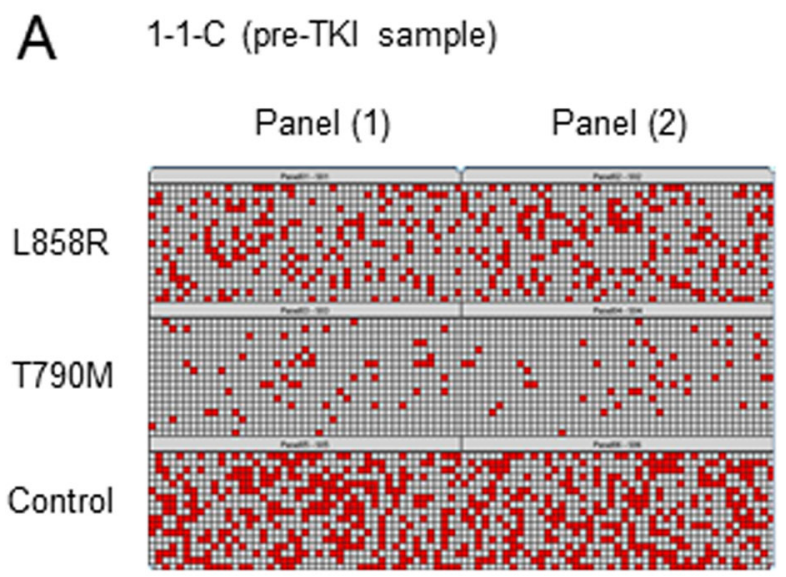

B $\quad 1-2-C$ (post-TKI sample)

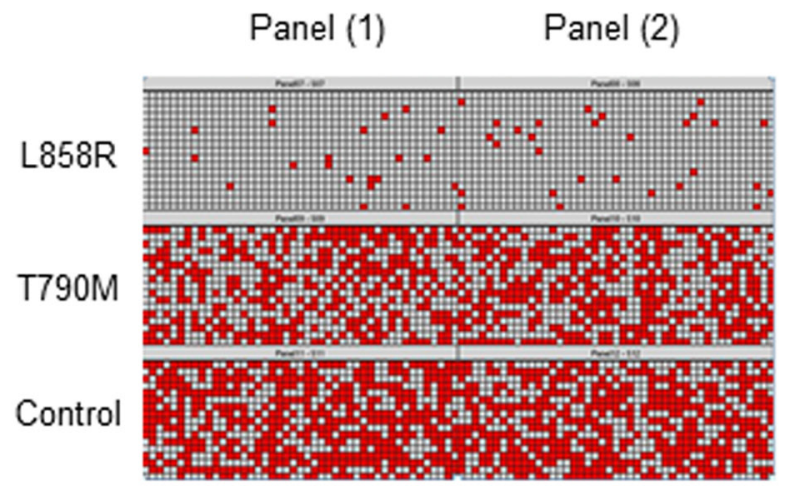

Input DNA (ng) applied to each panel

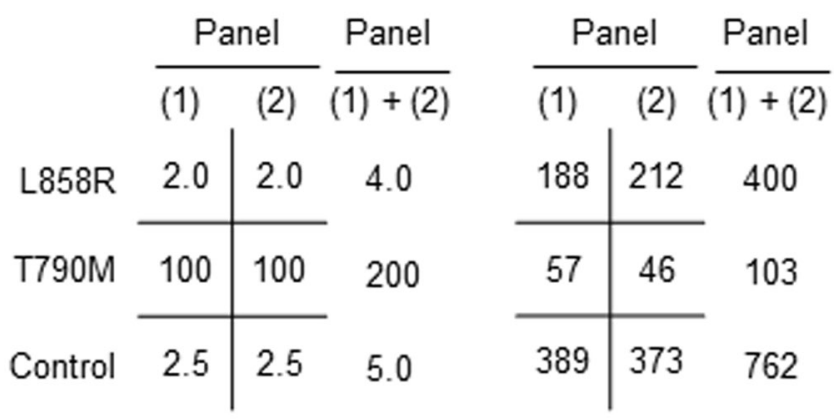

\section{Estimated number of target alleles (by Poisson distribution)}

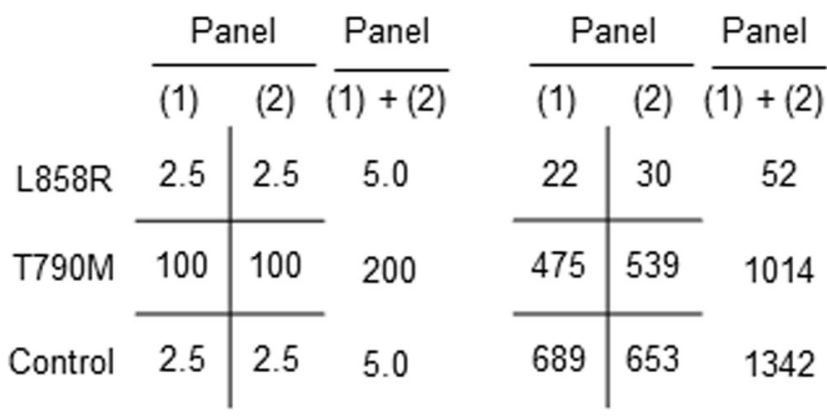

Figure 2: Representative results for quantitative evaluation of T790M by dPCR. Two samples were obtained from the same patient (no. 1) either before (sample 1-1-C, pre-TKI) (A) or after (sample 1-2-C, post-TKI) (B) EGFR-TKI treatment. The assay was performed in duplicate [panels (1) and (2)]. Chambers with a positive reaction are indicated as red squares in a heat map for each of the 765 chambers, and the number of signals was counted by system software (raw data). 


\section{Quantitative change in T790M frequency during EGFR-TKI treatment}

To evaluate the quantitative change in T790M frequency during EGFR-TKI treatment, we also calculated T/A (\%) for post-TKI samples. Representative results for a post-TKI sample (1-2-C) obtained from the same patient (no. 1) as the representative pre-TKI sample are shown in Figure 2B. We found that: $\mathrm{L} 858 \mathrm{R} / \mathrm{control}=(52 \times 5.0) /$ $(1342 \times 5.0)=3.87 \%(c), \mathrm{T} 790 \mathrm{M} /$ control $=(1014 \times 5.0) /$ $(1342 \times 200)=1.89 \%(d)$, and $\mathrm{T} / \mathrm{A}=d / c=1.89 / 3.87=$ $48.84 \%$, indicating that the frequency of T790M alleles increased during EGFR-TKI treatment in this patient. The T/A (\%) values for all 12 post-TKI samples are shown in Table 2 and Supplementary Table 2.

Both pre-TKI and post-TKI samples were available for seven patients (nos.1 to 7). These seven patients received EGFR-TKI treatment for more than 10 months with substantial clinical benefit (Table 1). In six (85.7\%) of these seven patients, the T/A value was greater after EGFR-TKI treatment than before (Figure 3).

\section{DISCUSSION}

Up to $60 \%$ of individuals with NSCLC who develop resistance to EGFR-TKIs have been found to harbor the T790M secondary mutation of EGFR. This mutation has also been detected in NSCLC patients before EGFRTKI treatment, however, with a detection rate ranging from $\sim 30 \%$ to $\sim 80 \%$ depending on the sensitivity of the detection technique [16-19]. In the present study, we have demonstrated the presence of the T790M mutation in all tumor specimens obtained from NSCLC patients with activating $E G F R$ mutations regardless of whether the samples were obtained before or after EGFR-TKI treatment. The estimated number of control alleles applied to reaction panels for detection of T790M was limited to $<1.0 \times 10^{5}$ in all samples so as not to generate a false positive result. Given that the estimated number of T790M alleles was $>3$ when the applied number of control alleles was $>1.0 \times 10^{4}$ (Supplementary Table 3 ), the present study was performed within the reliable range for specificity of $\mathrm{dPCR}$. The finding that $\mathrm{T} 790 \mathrm{M}$ was present in all samples is therefore not a false positive.

There are several possible explanations for the higher detection rate of $\mathrm{T} 790 \mathrm{M}$ in the present study compared with previous studies. First, the DNA analyzed in our study was evaluated by three techniques (NanoDrop, Qubit, and ARMS) for determination of an adequate and appropriate amount for application to dPCR. Given that NanoDrop overestimates the concentration of DNA, especially for tumor samples in which DNA is partially degraded, the combination of this system with measurement of double-stranded DNA (dsDNA) by Qubit is helpful for evaluation of a suitable amount of DNA for PCR [24]. The isolated DNA was also evaluated in terms of the cycle threshold $\left(C_{t}\right)$ value obtained by ARMS, which provides a measure of DNA quantity and suitability for PCR amplification. Second, we used cytological specimens or frozen cell pellets, which are free from the effect of formalin fixation on DNA integrity. Formaldehyde has been found to induce both the formation of cross-links between DNA and proteins as well as fragmentation of DNA [25]. In our study, the concentration of dsDNA obtained from formaldehyde-free samples was thus adequate for PCR as reflected by the low $C_{\mathrm{t}}$ values obtained by ARMS targeting the control allele

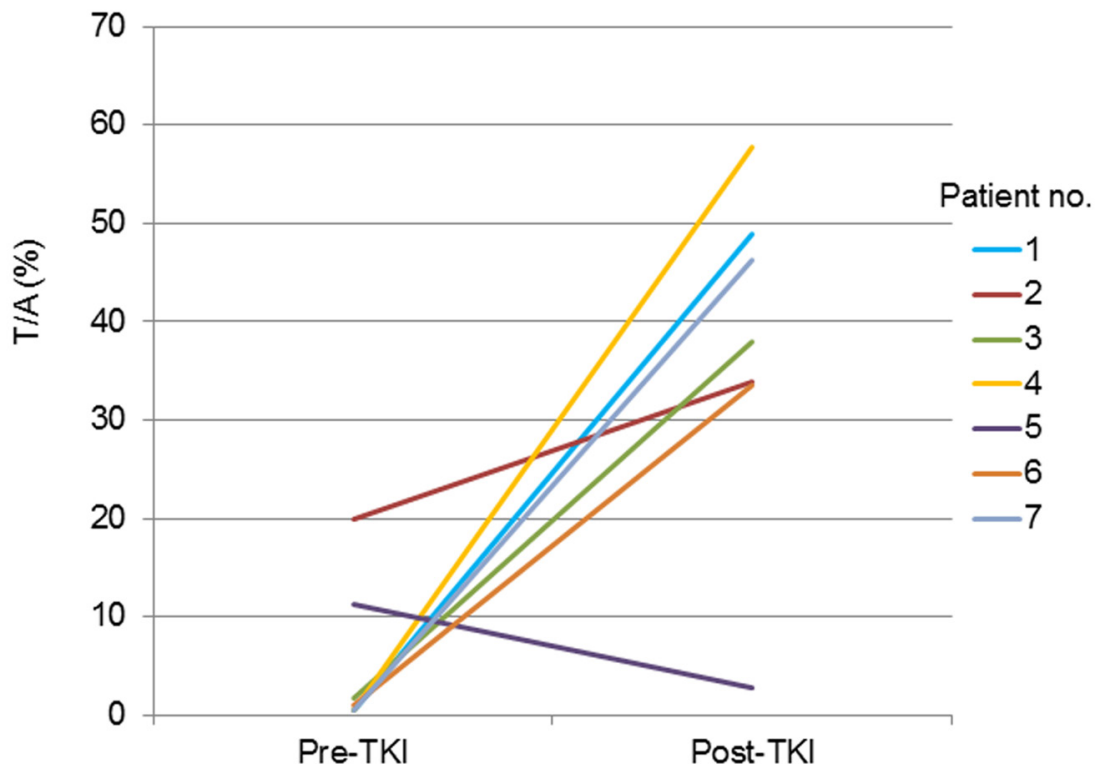

Figure 3: Quantitative change in the T/A ratio for the seven patients for whom both pre-TKI and post-TKI samples were available. 
(Supplementary Table 4).

In our study, T790M was detected in all 13 preTKI samples, and 12 of the corresponding patients were subsequently treated with EGFR-TKIs (Table 1). Ten of these 12 patients (nos. 1 to 3 and 5 to 11) had a low T/A value for the pre-TKI sample and experienced substantial tumor shrinkage during treatment with gefitinib or erlotinib (Tables 1 and 2), consistent with the previous finding that gefitinib or erlotinib was effective for the treatment of tumors estimated to have a low frequency of T790M by ARMS [26]. Administration of first-generation EGFR-TKIs such as gefitinib and erlotinib should thus not be avoided in T790M-positive patients if the T/A ratio in the pre-TKI sample is low. This conclusion is supported by a previous in vitro study with PC9 cells, which harbor an activating EGFR mutation (Ex19 del). The presence of a small proportion of cells that also harbor T790M was thus found not to substantially affect overall sensitivity to erlotinib [27]. Sensitivity to erlotinib declined, however, as the proportion of T790M-positive cells increased. In our study, the T/A ratio increased during EGFR-TKI treatment in six of the seven patients for whom both pre-TKI and post-TKI samples were available. Our results thus support the notion that tumor cells harboring T790M are present in small numbers even before EGFR-TKI treatment, and that these T790M-positive cells undergo selection and enrichment during such treatment [26]. The presence of T790M was likely responsible for the development of acquired resistance to EGFR-TKIs in these latter six patients of the present study. In the case of patient no. 5, whose T/A ratio did not increase after failure of gefitinib treatment, another resistance mechanism, such as $M E T$ amplification, may have been operative and responsible for resistance to the drug.

There are several limitations to our study. First, the study is retrospective and has a small sample size. Second, in most cases, cytotoxic chemotherapy was performed between the collection of pre-TKI and post-TKI samples (Table 1). The possibility therefore exists that the change in the T/A ratio was not solely attributable to selection of T790M-positive cells by EGFR-TKI treatment in such cases. Third, most specimens were obtained from metastatic lesions rather than from primary tumors, giving rise to the possibility that our results may not reflect the status of T790M in primary lesions. Finally, pre- and postTKI samples were obtained from different sites in several cases, raising the possibility that the quantitative change in T790M frequency may have been due to intratumoral heterogeneity.

In conclusion, when highly sensitive methods such as $\mathrm{dPCR}$ or next-generation sequencing (NGS) are introduced into clinical practice in the near future, T790M will be detected with a high frequency in NSCLC cases positive for activating EGFR mutations regardless of whether the patient has been treated with EGFR-TKIs or not. Quantitative evaluation of T790M on the basis of the T/A ratio will therefore be important to determine whether T790M is likely to be responsible for EGFR-TKI resistance in such patients. Given that high-coverage NGS is also able to determine allele frequencies, a study that applies both APCR and NGS in more patients is warranted.

\section{MATERIALS AND METHODS}

\section{Sample preparation}

Cells in $\mathrm{C}$ samples were scraped from the glass slide with a surgical blade after removal of the cover slip by overnight incubation in xylene. DNA was extracted from the cells with the use of a QIAamp FFPE Tissue Kit (Qiagen KK, Tokyo, Japan). Malignant effusion specimens had been centrifuged at $630 \times g$ for $10 \mathrm{~min}$ at room temperature, and the cell pellets had been stored at $-80^{\circ} \mathrm{C}$ (F samples). DNA was extracted from these samples with a QIAamp DNA Mini Kit (Qiagen KK) according to the blood and body fluid spin protocol in the manufacturer's instructions. The concentration and purity of extracted DNA in all samples were determined by spectrophotometry (NanoDrop ND-1000; Thermo Fisher Scientific, Waltham, MA). dsDNA was quantified with the use of a Quant-iT dsDNA HS Assay (Life Technologies, Carlsbad, CA) and a Qubit fluorometer (Life Technologies). The extracted DNA was stored at $4^{\circ} \mathrm{C}$ until analysis.

\section{Scorpion ARMS}

We performed allele-specific PCR by Scorpion ARMS with the use of a Therascreen EGFR RGQ PCR Kit (Qiagen KK) as a conventional method to detect three targets (control, activating mutations, and T790M). We included 20 ng of DNA (as determined with NanoDrop) in each reaction. A region of exon 2 of $E G F R$ was amplified as the control. ARMS reveals the number of PCR cycles necessary to detect the target molecule present at the beginning of the reaction. The cycle number at which the signal is detected above background fluorescence is defined as the cycle threshold $\left(C_{\mathrm{t}}\right)$. A sample is considered to be positive for the target mutation if the difference between its mutation $C_{\mathrm{t}}$ value and its control $C_{\mathrm{t}}$ value is less than the cutoff value described in the manufacturer's instructions.

\section{Nanofluidic dPCR}

We used a nanofluidic dPCR system (BioMark HD System; Fluidigm, South San Francisco, CA) with the Fluidigm digital chip to quantitate target DNA molecules. The digital chip delivers up to 12 mixtures of samples 
and PCR reagents into 12 individual panels. Each panel contains 765 independent 6-nl chambers. We estimated an appropriate amount of DNA to be applied to each panel that would yield positive signals in some but not all $(n=$ 765) chambers on the basis of the $C_{t}$ values of each target allele obtained with ARMS. The individual target DNA molecules become randomly distributed in the chambers after their addition. ARMS was performed in each reaction chamber targeting either control (region of exon 2), activating mutation (L858R or Ex19 del), or T790M alleles of EGFR. After 35 cycles of PCR, the number of signals obtained from successfully reacted chambers was counted with the Fluidigm digital PCR analysis software (raw data). The number of target alleles included in each sample was then estimated on the basis of the raw data with the use of the Poisson distribution, given that a positive reaction in a chamber may correspond to multiple target molecules.

\section{Statistical analysis}

Statistical analysis was performed with the use of JMP version 9 software (SAS Institute, Cary, NC). We used Poisson regression analysis to decide the cutoff point for the specificity of dPCR.

\section{ACKNOWLEDGMENTS}

We thank Atsushi Kakimoto of the Center for Molecular Biology and Cytogenetics at $S R L$ Inc. for technical support.

\section{FUNDING}

This work was supported by a research program of the Project for Development of Innovative Research on Cancer Therapeutics (P-DIRECT), Ministry of Education, Culture, Sports, Science, and Technology of Japan, as well as in part by the Fukuoka Foundation for Sound Health (2013).

\section{CONFLICTS OF INTEREST}

The authors have declared no conflicts of interest.

\section{REFERENCES}

1. Mok TS, Wu YL, Thongprasert S, Yang CH, Chu DT, Saijo N, Sunpaweravong P, Han B, Margono B, Ichinose Y, Nishiwaki Y, Ohe Y, Yang JJ, et al. Gefitinib or carboplatin-paclitaxel in pulmonary adenocarcinoma. N Engl J Med. 2009;361:947-957.

2. Maemondo M, Inoue A, Kobayashi K, Sugawara S, Oizumi $\mathrm{S}$, Isobe $\mathrm{H}$, Gemma A, Harada M, Yoshizawa H, Kinoshita I, Fujita Y, Okinaga S, Hirano H, et al. North-East Japan
Study Group: Gefitinib or chemotherapy for non-smallcell lung cancer with mutated EGFR. N Engl J Med. 2010;362:2380-2388.

3. Mitsudomi T, Morita S, Yatabe Y, Negoro S, Okamoto I, Tsurutani J, Seto T, Satouchi M, Tada H, Hirashima T, Asami K, Katakami N, Takada M, et al. West Japan Oncology Group: Gefitinib versus cisplatin plus docetaxel in patients with non-small-cell lung cancer harbouring mutations of the epidermal growth factor receptor (WJTOG3405): an open label, randomised phase 3 trial. Lancet Oncol. 2010;11:121-128.

4. Rosell R, Carcereny E, Gervais R, Vergnenegre A, Massuti B, Felip E, Palmero R, Garcia-Gomez R, Pallares C, Sanchez JM, Porta R, Cobo M, Garrido P, et al. Spanish Lung Cancer Group in collaboration with Groupe Francais de Pneumo-Cancerologie and Associazione Italiana Oncologia Toracica: Erlotinib versus standard chemotherapy as first-line treatment for European patients with advanced EGFR mutation-positive non-small-cell lung cancer (EURTAC): a multicentre, open-label, randomised phase 3 trial. Lancet Oncol. 2012;13:239-246.

5. Zhou C, Wu YL, Chen G, Feng J, Liu XQ, Wang C, Zhang S, Wang J, Zhou S, Ren S, Lu S, Zhang L, Hu C, et al. Erlotinib versus chemotherapy as first-line treatment for patients with advanced EGFR mutation-positive non-smallcell lung cancer (OPTIMAL, CTONG-0802): a multicentre, open-label, randomised, phase 3 study. Lancet Oncol. 2011;12:735-742.

6. Sequist LV, Yang JC, Yamamoto N, O’Byrne K, Hirsh V, Mok T, Geater SL, Orlov S, Tsai CM, Boyer M, Su WC, Bennouna J, Kato T, et al. Phase III study of afatinib or cisplatin plus pemetrexed in patients with metastatic lung adenocarcinoma with EGFR mutations. J Clin Oncol. 2013;31:3327-3334.

7. Wu YL, Zhou C, Hu CP, Feng J, Lu S, Huang Y, Li W, Hou M, Shi JH, Lee KY, Xu CR, Massey D, Kim M, et al. Afatinib versus cisplatin plus gemcitabine for first-line treatment of Asian patients with advanced non-small-cell lung cancer harbouring EGFR mutations (LUX-Lung 6): an open-label, randomised phase 3 trial. Lancet Oncol. 2014;15:213-222.

8. Newton CR, Graham A, Heptinstall LE, Powell SJ, Summers C, Kalsheker N, Smith JC, Markham AF. Analysis of any point mutation in DNA. The amplification refractory mutation system (ARMS). Nucleic Acids Res. 1989; 17:2503-2516.

9. Ellison G, Donald E, McWalter G, Knight L, Fletcher L, Sherwood J, Cantarini M, Orr M, Speake G. A comparison of ARMS and DNA sequencing for mutation analysis in clinical biopsy samples. J Exp Clin Cancer Res. 2010;29:132-9966-29-132.

10. Goto K, Satouchi M, Ishii G, Nishio K, Hagiwara K, Mitsudomi T, Whiteley J, Donald E, McCormack R, Todo T. An evaluation study of EGFR mutation tests utilized for non-small-cell lung cancer in the diagnostic setting. Ann 
Oncol. 2012;23:2914-2919.

11. Ellison G, Zhu G, Moulis A, Dearden S, Speake G, McCormack R. EGFR mutation testing in lung cancer: a review of available methods and their use for analysis of tumour tissue and cytology samples. J Clin Pathol. 2013;66:79-89.

12. Mitsudomi T, Yatabe Y. Mutations of the epidermal growth factor receptor gene and related genes as determinants of epidermal growth factor receptor tyrosine kinase inhibitors sensitivity in lung cancer. Cancer Sci. 2007;98:1817-1824.

13. Sequist LV, Waltman BA, Dias-Santagata D, Digumarthy S, Turke AB, Fidias P, Bergethon K, Shaw AT, Gettinger $\mathrm{S}$, Cosper AK. Akhavanfard S, Heist RS, Temel J, Christensen JG, Wain JC, Lynch TJ, Vernovsky K, Mark EJ, Lanuti M, Iafrate AJ, Mino-Kenudson M, Engelman JA: Genotypic and histological evolution of lung cancers acquiring resistance to EGFR inhibitors. Sci Transl Med. 2011;3:75ra26.

14. Kobayashi S, Boggon TJ, Dayaram T, Janne PA, Kocher O, Meyerson M, Johnson BE, Eck MJ, Tenen DG, Halmos B. EGFR mutation and resistance of non-small-cell lung cancer to gefitinib. N Engl J Med. 2005;352:786-792.

15. Yu HA, Arcila ME, Rekhtman N, Sima CS, Zakowski MF, Pao W, Kris MG, Miller VA, Ladanyi M, Riely GJ. Analysis of tumor specimens at the time of acquired resistance to EGFR-TKI therapy in 155 patients with EGFR-mutant lung cancers. Clin Cancer Res. 2013;19:2240-2247.

16. Rosell R, Molina MA, Costa C, Simonetti S, GimenezCapitan A, Bertran-Alamillo J, Mayo C, Moran T, Mendez $\mathrm{P}$, Cardenal F, Isla D, Provencio M, Cobo $\mathrm{M}$, et al. Pretreatment EGFR T790M mutation and BRCA1 mRNA expression in erlotinib-treated advanced non-small-cell lung cancer patients with EGFR mutations. Clin Cancer Res. 2011;17:1160-1168.

17. Su KY, Chen HY, Li KC, Kuo ML, Yang JC, Chan WK, Ho BC, Chang GC, Shih JY, Yu SL, Yang PC. Pretreatment epidermal growth factor receptor (EGFR) T790M mutation predicts shorter EGFR tyrosine kinase inhibitor response duration in patients with non-small-cell lung cancer. J Clin Oncol. 2012;30:433-440.

18. Fujita Y, Suda K, Kimura H, Matsumoto K, Arao T, Nagai T, Saijo N, Yatabe Y, Mitsudomi T, Nishio K. Highly sensitive detection of EGFR T790M mutation using colony hybridization predicts favorable prognosis of patients with lung cancer harboring activating EGFR mutation. J Thorac Oncol. 2012;7:1640-1644.

19. Costa C, Molina MA, Drozdowskyj A, Gimenez-Capitan A, Bertran-Alamillo J, Karachaliou N, Gervais R, Massuti B, Wei J, Moran T, Majem M, Felip E, Carcereny E, et al. The impact of EGFR T790M mutations and BIM mRNA expression on outcome in patients with EGFRmutant NSCLC treated with erlotinib or chemotherapy in the randomized phase III EURTAC trial. Clin Cancer Res. 2014;20:2001-2010.

20. Yung TK, Chan KC, Mok TS, Tong J, To KF, Lo YM.
Single-molecule detection of epidermal growth factor receptor mutations in plasma by microfluidics digital PCR in non-small cell lung cancer patients. Clin Cancer Res. 2009;15:2076-2084.

21. Wang J, Ramakrishnan R, Tang Z, Fan W, Kluge A, Dowlati A, Jones RC, Ma PC. Quantifying EGFR alterations in the lung cancer genome with nanofluidic digital PCR arrays. Clin Chem. 2010;56:623-632.

22. Azuara D, Ginesta MM, Gausachs M, Rodriguez-Moranta F, Fabregat J, Busquets J, Pelaez N, Boadas J, Galter S, Moreno V, Costa J, de Oca J, Capella G. Nanofluidic digital PCR for KRAS mutation detection and quantification in gastrointestinal cancer. Clin Chem. 2012;58:1332-1341.

23. Dawson SJ, Tsui DW, Murtaza M, Biggs H, Rueda OM, Chin SF, Dunning MJ, Gale D, Forshew T, MahlerAraujo B, Rajan S, Humphray S, Becq J, et al. Analysis of circulating tumor DNA to monitor metastatic breast cancer. N Engl J Med. 2013;368:1199-1209.

24. Simbolo M, Gottardi M, Corbo V, Fassan M, Mafficini A, Malpeli G, Lawlor RT, Scarpa A. DNA qualification workflow for next generation sequencing of histopathological samples. PLoS One. 2013;8:e62692.

25. Schweiger MR, Kerick M, Timmermann B, Albrecht MW, Borodina T, Parkhomchuk D, Zatloukal K, Lehrach H. Genome-wide massively parallel sequencing of formaldehyde fixed-paraffin embedded (FFPE) tumor tissues for copy-number- and mutation-analysis. PLoS One. 2009;4:e5548.

26. Maheswaran S, Sequist LV, Nagrath S, Ulkus L, Brannigan B, Collura CV, Inserra E, Diederichs S, Iafrate AJ, Bell DW, Digumarthy S, Muzikansky A, Irimia D, et al. Detection of mutations in EGFR in circulating lung-cancer cells. N Engl J Med. 2008;359:366-377.

27. Chmielecki J, Foo J, Oxnard GR, Hutchinson K, Ohashi K, Somwar R, Wang L, Amato KR, Arcila M, Sos ML, Socci ND, Viale A, de Stanchina E, et al. Optimization of dosing for EGFR-mutant non-small cell lung cancer with evolutionary cancer modeling. Sci Transl Med. 2011;3:90ra59. 